\title{
User Site Testing
}

National Cancer Institute

\section{Source}

National Cancer Institute. User Site Testing. NCI Thesaurus. Code C142746.

Any examination of software/hardware functionality that takes place outside of the developer's controlled environment. 